\title{
Inter Terminal Transport in Port Areas around the Globe
}

\author{
Qu Hu${ }^{1}$, Francesco ${ }^{2}$, Corman ${ }^{3}$ and Bart Wiegmans ${ }^{3,4 *}$ \\ ${ }^{1}$ Deppartment of Marine and Transport Technology, Delft University of Technology, Netherlands \\ ${ }^{2}$ Swiss Federal Institute of Technology ETH Zurich, Switzerland \\ ${ }^{3}$ Department of Transport \& Planning, Delft University of Technology, Netherlands \\ ${ }^{4}$ Associate Transport Institute, University of Manitoba, Canada \\ *Corresponding author: Bart Wiegmans, Delft University of Technology, Netherlands, Tel: +31 06843 46 191; Email: Q.Hu@tudelft.nl \\ Submission: 㭗April 16, 2018; Published: 畊 May 03, 2018
}

Abbreviations: MTS: Multi-Trailer System; AGV: Automated Guided Vehicle; ALV: Automated Lifting Vehicle; ITT: Inter-Terminal Transport

\section{Editorial}

Generally, inter-terminal transport (ITT) refers to the container transport between terminals and service centers (e.g., empty depots) using any type of transport modes Duinkerken et al. [1], Heilig \& Voss [2]. Moving containers between terminals inside a port might seem unreasonable as it leads to extra service time and cost. However, ITT is somehow inevitable in most major ports, and the reason could be twofold.

Firstly, to handle the increasing and various containerized transport demand, major ports are improving themselves both in size and accessibility. Usually, in a port area, there may exist different terminals (deep-sea terminals, barge terminals, railway terminals and empty depots) connected with different transport modalities (road, rail, barge and sea). In order to make full use of all terminals and modalities, containers are often exchanged between terminals and modalities. Then, containers are also moved between terminals and service centers. For example, empty containers are distributed among several terminals and empty depots according to the demand, inventory cost and transport cost Hjortnaes et al.. Consequently, containers are not only handled inside one terminal, but also transported between several terminals in port areas.

To reduce the ITT service time and cost, different ITT systems have been studied in the last decades. Ottjes et al. [3] introduced one of the first ITT systems. The system was aimed to connect the onshore terminals with barge, which could reduce the congestion caused by road ITT. With the development of information and control technology, ITT systems with advanced dispatching systems and self-driven vehicles are studied. In Hansen [4], self-driven railcars were used to move containers between different rail yards. Duinkerken et al. [1] compared the performance of ITT systems with multi-trailer system (MTS), automated guided vehicle (AGV), and automated lifting vehicle (ALV). In Heilig et al. [2], a cloudbased information platform was introduced. The platform collects information about transport demand, location of available trucks and traffic condition and send dispatching orders to truck drivers.

Although considerable effort has been put into ITT research, ITT planning is still challenging. On the strategic level, it is difficult to determine who should invest in the infrastructure (berth, road, handling equipment, etc.), information system, and fleet. In the existing research, it is usually assumed that the ITT service is provided by a third party ITT provider. The port authority, terminal operator, shipping company, freight forwarders and logistic service providers may all have the motivation to improve the ITT service, which could increase the port competitiveness, reduce terminal handling cost, shipping cost, etc., but it is not clear to what extent they can benefit from the investment. Therefore, it is not clear how much each actor should pay for the ITT system and which benefits are to be expected by which actors.

On tactical level, it is also difficult to determine whether a terminal should be involved in the ITT service network. In existing research, the studied ITT service is usually provided to terminals with the same operator. In reality, terminals in a port are usually operated separately; therefore, a certain cooperation agreement must be established between different terminal operators and the information about demand, handling and transport capacity must be shared and coordinated. The cost for the cooperation is hard to estimate and thus it is not clear whether a terminal should join the ITT service network.

On operational level, the planning of ITT operations requires advanced decision support system. On one hand, the operational planning decisions must be made considering the conflict interests 
of different actors. On the other hand, the coordination between different transport modes, the interaction between ITT and terminal handling operations, deep-sea or hinterland transport must be considered. Therefore, the decision support system must be able to collect adequate information and provide reasonable solution. In short, the ITT system involves coordination between multiple actors and integration between multiple operations, which increase the difficulty in responsibility/benefit division and operational optimization. There are several research gaps to be filled to improve the planning of ITT system.

\section{References}

1. Duinkerken MB, Dekker R, Kurstjens STGL, Ottjes JA, Dellaert NP (2006) Comparing transportation systems for inter-terminal transport at the Maasvlakte container terminals. Or Spectrum 28(4): 469-493.
2. Heilig L, Voss S (2017) Inter-terminal transportation: an annotated bibliography and research agenda. Flexible Services and Manufacturing Journal 29(1): 35-63.

3. Ottjes JA, Hengst S, Tutuarima WH (1994) A simulation model of a sailing container terminal service in the port of Rotterdam. In Proceedings of the 1994 Conference on Modelling and Simulation, Delft University of Technology, The Netherlands, pp. 876-880.

4. Hansen IA (2004) Automated shunting of rail container wagons in ports and terminal areas. Transportation Planning and Technology 27(5): 385-401.
Creative Commons Attribution 4.0 International License

For possible submissions Click Here

\section{Submit Article}

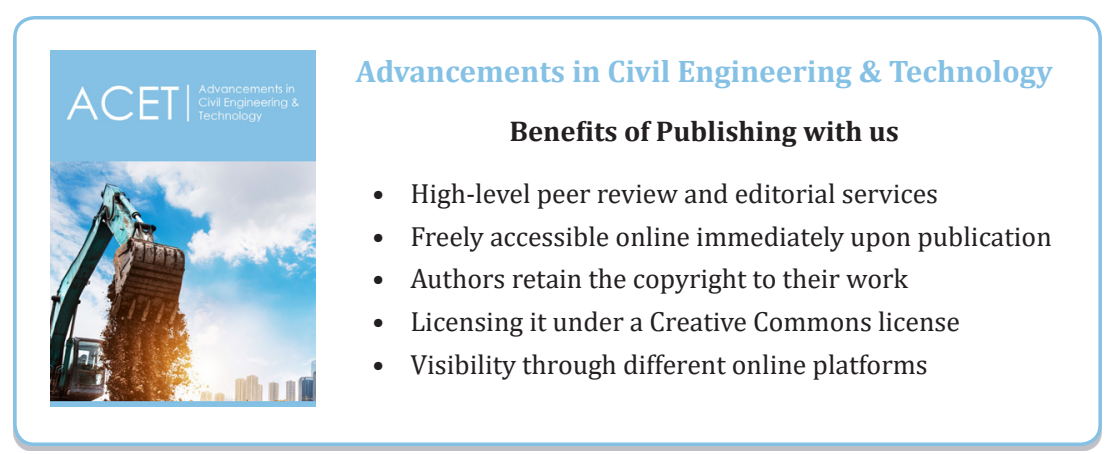

